\title{
La cristología poética de Pedro Casaldáliga
}

A dom Pedro, maestro

A Gerardo, compañero

\section{Michael P. Moore \\ Facultad de Teología, Universidad del Salvador San Miguel, Argentina}

\section{Introducción}

Todo hablar sobre Dios es un balbuceo ante el Misterio. Y esto rige sobre todo lenguaje: atañe a la palabra teológica, a la filosófica, a la poética... El desafío es grande, como grande es la necesidad de hacerlo. Consciente de esa tensión, el poeta se anima a romper el silencio original.

Derramando palabras,

de mis silencios vengo

y a mis silencios voy.

$\mathrm{Y}$ en Tus silencios labras

el grito que sostengo

y el silencio que soy ${ }^{1}$.

En cuanto creyente cristiano, la condición de posibilidad de referirse al Misterio es el decir-Se primero de Dios en la historia y la carne de Jesús, el Cristo. El Dios de quien quiere hablar Casaldáliga es "el Dios de Jesucristo", es decir, el que puede conocerse a partir de la revelación histórica en la vida, la muerte y la resurrección de ese judío marginal, intentando evitar posibles apriorismos derivados de la tendencia innata en todos los hombres de todos los

1. El tiempo y la espera, p. 17 (Santander, 1986). Salvo que se nombre expresamente otro autor, las obras citadas corresponden a Pedro Casaldáliga. En las referencias bibliográficas se listan los títulos de los poemas y las páginas del libro citado donde se encuentran. 
tiempos a construir a Dios a su imagen y semejanza, distorsionando así lo que significa tanto su divinidad como nuestra filiación ${ }^{2}$. En este error cayeron $-\mathrm{y}$ siguen cayendo - todos los discursos que deducen, de una idea previa de Dios, lo que debe ser Jesús en cuanto Dios encarnado. El resultado es tanto una falsificación de su humanidad como de su divinidad ${ }^{3}$. Por eso, pide nuestro autor:

Dinos cuál es tu Dios, Jesús; enséñanos

a no hacerlo el Dios que no lo haces.

¡Devuélvenos tu Dios, mostrándonos el Padre! ${ }^{4}$

Claro que este punto de partida no exime del peligro de tergiversación, de un conocimiento direccionado al uso y al abuso, a la manipulación ideológica. La pregunta y la duda que inquieta deben acompañar, críticamente, al propio discurso. Así manifiesta esta preocupación, constante, con las primeras palabras con que comienza el soneto titulado "Jesús de Nazaret".

¿Cómo dejarte ser solo Tú mismo,

sin reducirte, sin manipularte?

¿Cómo, creyendo en $\mathrm{Ti}$, no proclamarte

igual, mayor, mejor que el Cristianismo? ${ }^{5}$

Desde estos presupuestos, el presente trabajo intenta mostrar algunos trazos de la concepción cristológica de Pedro Casaldáliga, según se esboza en parte de su obra poética ${ }^{6}$. De origen español, pero plenamente encarnado en el modo de pensar, sentir y vivir de este continente empobrecido, su obra literaria tiene como

2. Cf. J. I. González Faus, Acceso a Jesús: ensayo de teología narrativa, pp. 20-21 (Salamanca, 1979).

3. "Se presuponen conceptos que precisamente desde Jesús no se pueden presuponer: qué es ser Dios y qué es ser hombre. Es decir, no se puede propiamente explicar la figura de Jesús a partir de conceptos supuestamente ya conocidos previamente a Jesús, puesto que lo que viene a cuestionar Jesús es la comprensión de Dios y del hombre. 'Divinidad' y 'humanidad' pueden servir como definiciones nominales para romper de alguna manera el círculo hermenéutico, pero no como definiciones reales ya conocidas para entender a Jesús; el movimiento debe ser más bien el contrario". J. Sobrino, Cristología desde América Latina, p. 82 (México D. F., 1976).

4. Todavía estas palabras (Estela, 1989). Disponible en http://servicioskoinonia.org/ Casaldaliga/poesia/todaviae.htm. Consulta el 1 de mayo de 2016.

5. Sonetos neobíblicos, precisamente, p. 29 (Buenos Aires, 1996).

6. Una buena introducción a esta temática se encuentra en V. Codina, "La teología poética de Pedro Casaldáliga, I", Revista Latinoamericana de Teología 12 (1987), 265-289; y en "La teología poética de Pedro Casaldáliga, II", Revista Latinoamericana de Teología 13 (1988), 45-65. Y de manera más amplia y contextuada, el reciente trabajo de P. Paganelli, $P(r) o(f)$ etas del reino. Literatura y teología de la liberación en Brasil, pp. 121-187 (Buenos Aires, 2015). 
trasfondo teológico los autores y los temas de la teología de nuestro continente, en especial, en su línea liberacionista. Así, encarnación y reino se constituyen en categorías centrales de su cristología, analizadas aquí en su expresión poética. En este cruce entre teología y literatura, la vida y la obra de Casaldáliga emergen en América Latina como una de las más lúcidas e interpelantes figuras del amor hecho historia, testigo de la Palabra hecha carne y de la carne hecha reino en su vida y con su vida.

Sabedor del misterio de Dios, del misterio que es Dios, "Ninguna lengua a Su verdad se atreve / Nadie lo ha visto a Dios. Nadie lo sabe" , escribe don Pedro, mientras, con su palabra valiente, "se atreve" y nos acompaña para asomarnos y asombrarnos ante el Misterio, consciente - con realismo evangélico - del peligro de referirse a esa realidad con poesías que anuncian y denuncian.

Te llamarán poeta

para reírse de tus razones

que desentonan de su razón;

para zafarse de tu Evangelio

que les cuestiona a su propio Dios.

Te llamarán profeta

para exigirte lo que no son,

para llevarte hasta la muerte

y darte un póster en su salón ${ }^{8}$.

\section{La Palabra se hizo carne...}

La idea de encarnación nos quiere decir que lo humano de Jesús es transparencia de Dios. La historia humana de aquel hombre es revelación de "lo humano de Dios"; y si un elemento de nuestra historia, una "humanidad", es palabra, comunicación de Dios, esto significa que Dios no es algo extraño respecto de esta historia, ni tampoco un irruptor advenedizo. Y, por lo tanto, el hombre no necesita salir de esta historia para encontrar a Dios ${ }^{9}$.

¿Por dónde iréis hasta el cielo

si por la tierra no vais?

¿Para quién vais al Carmelo, si subís y no bajáis? ${ }^{10}$

7. Sonetos, o. c., p. 19.

8. Todavía, o. c., http://servicioskoinonia.org/Casaldaliga/poesia/todaviae.htm.

9. Cf. J. I. González Faus, El factor cristiano, pp. 23-24 (Córdoba-Argentina, 2004).

10 El tiempo, o. c., p. 35. 


\section{1. “Sus manos y sus pies de tierra llenos": encarnación y kénosis}

La pretensión inaudita del cristianismo radica en afirmar que en Jesús-Cristo, "le hemos visto el rostro a Dios". Jesús es el rostro humano de Dios, y por eso, desde ahí, podemos atrevernos a columbrar - con temor y temblor- algo de su verdad. Pero ese aparecer de Dios en carne humana no es neutral, es decir, la encarnación, siendo el misterio central de nuestra fe, no es "aséptica". Dios no solo se hace hombre, sino que se hace un hombre con una humanidad concreta, en un tiempo y en un lugar, con una condición social, económica, socio-religiosa, etc., bien determinadas, que hablan, de algún modo, de las opciones preferenciales de nuestro Dios.

En el vientre de María

Dios se hizo hombre.

Y en el taller de José

Dios se hizo también clase ${ }^{11}$.

Por eso, conviene calificar, ¡sustantivar!, la encarnación como kénosis. No solo hombre, sino, de alguna forma, negatividad humana: esclavo, siervo, pobre, maldición. Así, la dialéctica revelación-ocultamiento aparece teñida de lógica kenótica.

Eres un Dios escondido,

pero en la carne de un hombre.

Eres un Dios escondido

en cada rostro de pobre.

Más tu Amor se nos revela

cuanto más se nos esconde ${ }^{12}$.

El soneto "Él se hizo uno de tantos", donde Casaldáliga aborda directamente el tema de la encarnación, comienza señalando que la condición de posibilidad para que la palabra poética pueda nombrarlo, es su decir-Se primero, anonadándose, dado que "En la oquedad de nuestro barro breve / el mar sin nombre de Su luz no cabe"13. Pero lo que es imposible para el hombre, no lo es para Dios ( $c f$. Lc 18,27), y por eso, "El Unigénito venido a menos / traspone la distancia en un vagido"14. En el diálogo que es la revelación, la iniciativa, la palabra primera (iy última!), le corresponden a Dios. La palabra teológica, filosófica y, o poética siempre es respuesta. Y esto que parece obvio, no lo ha sido tanto en los distintos discursos sobre Dios, porque muchas veces se ha caído en esos nocivos apriorismos (¿inocentes?) a los que nos referimos en la introducción, cuando en

11. Con Jesús, el de Nazaret, p. 21 (Madrid, 2005).

12. Todavía, o. c., http://servicioskoinonia.org/Casaldaliga/poesia/todaviae.htm.

13. Sonetos, o. c., p. 19.

14. Ibidem. 
realidad "no se sabe exactamente quién es Dios sino a la luz de la realización historificada de Dios en Jesús"15.

Precisamente, unas de las "sanas obsesiones” de Casaldáliga resulta ser el afirmar de un modo claro y sin concesiones la humanidad de Jesucristo, lo que en lenguaje más teológico supone, entre otras cosas, "la vuelta al Jesús histórico"16. Así, por ejemplo, con un realismo sin anestesia, escribe: "ternura que en tu vientre cabe, / feto de sueño y sangre, nuestro Dios"17. Y alejando toda posible sombra de docetismo: "Sus manos y sus pies de tierra llenos"18. Claro que esta rotunda afirmación de la humanidad de Jesucristo no hipoteca la confesión de su divinidad, aunque sí la tiñe, al puntualizar lo escandaloso del modo: "¡versión de Dios en pequeñez humana!"'19. Y es que el verdadero problema, desde el punto de vista teológico y con claras consecuencias pastorales, no consiste tanto en afirmar ambas magnitudes, naturalezas, cuanto en precisar cómo se da la unidad en concreto y simultáneamente: Jesús no es Dios y hombre, sino que es Dios en su ser hombre; lo divino se nos da en lo no-divino. Dios se nos da Él mismo en lo otro de sí, en la creatura, que es la humanidad de Jesús, no además, por encima o al margen de ella ${ }^{20}$. Y en esta línea teológica, Casaldáliga subraya el empequeñecimiento de Dios en la pequeña carne de Jesús.

Así, por ejemplo, en el poema de dolorosa actualidad "Comadre de suburbio", que es un constante ir y venir del ayer al hoy, de Belén a Vallecas, Harlem o las favelas, presenta a nuestra contemplación cómo sería hoy el pesebre: entre paros y algunas changas, inmigrantes sin techo y sin subsidios.

La cueva no tenía más higiene que el viento de la noche.

Dios tuvo un vecindario de pobres amahares

-Vallecas o Belén, Belén o Harlem, Belén o las favelas-.

Tú tenías apenas las dos manos para alternar con ellas el pesebre.

Las ricas caravanas llegaban siempre a punto.

Vosotros llegaríais con las puertas cerradas.

No hubo piso en Belén; ni hubo piso en Egipto;

y no hay piso en Madrid, para vosotros.

José estará de paro forzoso muchos días.

Pero "con un hilo irrompible de alegría", paradoja que suele atravesar la vida de los pobres, orgullosos de una certeza que los enriquece porque

15. O. González de Cardedal, Jesús de Nazaret. Aproximación a la Cristología, p. 239 (Madrid, 1975).

16. Cf. Espiritualidad de la liberación, pp. 108-114 (Buenos Aires, 1993).

17. Sonetos, o. c., p. 27.

18. Sonetos, o. c., p. 19.

19. Ibidem.

20. Cf. J. I. González Faus, La humanidad nueva: ensayo de cristología, p. 580 (Santander, 1984). 
con el Verbo hecho carne que habita entre nosotros

tú has instalado a Dios en el suburbio humano ${ }^{21}$.

Dios se hace hombre... sin techo, sin trabajo, sin papeles... Y en un sentido poema mariano, "Mujer de cada día", pinta como en un cuadro, cadenciosamente, el contexto nazareno: cotidiano, silencioso, amable, pequeño, y allí apunta un detalle fundamental, pero muchas veces olvidado: la dimensión de la encarnación en el tiempo.

Y el Verbo se hace Hombre, día y noche,

delante de tus ojos,

al filo de tus manos,

detrás de tu silencio ${ }^{22}$.

En lenguaje más categorial, implica afirmar que la encarnación es una magnitud esencialmente histórica, no como posesión puntual de sí tota simul et perfecta, sino como llegar a ser lo que sin embargo ya se es desde siempre ${ }^{23}$. De esa manera, queda revalorizada la dimensión histórica, procesual, y permite vivir la filiación, a Jesús y a nosotros, como don y como tarea.

En esa misma dimensión temporal, ahora en perspectiva escatológica, Casaldáliga señala la continuidad en la discontinuidad de la propia identidad: seremos los mismos, pero no lo mismo, al igual que lo fue Jesús.

Y seremos nosotros, para siempre,

como eres Tú el que fuiste, en nuestra tierra,

hijo de la María y de la Muerte,

compañero de todos los caminos ${ }^{24}$.

Y es que, propiamente hablando, habría que afirmar que la encarnación no concluye sino con la resurrección: allí queda Jesús plenamente constituido el Hijo de Dios, con esa misma humanidad encarnada y crucificada que, conservando las llagas, ahora es glorificada.

Seremos los que somos, para siempre, pero gloriosamente restaurados, como son tuyas esas cinco llagas, imprescriptiblemente gloriosas ${ }^{25}$.

21. Antología personal, p. 21 (Madrid, 2006).

22. Ibid., p. 18.

23. Cf. J. I. González Faus, La humanidad nueva, o. c, p. 207.

24. Sonetos, o. c., p. 63.

25. Ibidem. 


\section{2. "Y el Verbo se hizo muerte, otra vez, en tu muerte": encarnación y cruz}

Si la verdad de la encarnación nos permite afirmar la divinización de la realidad, la actualidad de la cruz nos recuerda ahora con la misma claridad que ese proceso todavía no se ha completado. Y es que la encarnación es un concepto en tensión y dinámico: incluye en sí misma la kénosis y apunta intrínsecamente a la resurrección. La cruz de Jesús es aún cruz de la realidad y, por lo tanto, escondimiento de Dios en ella ${ }^{26}$. Axioma cristológico que para el poeta se convierte en imperativo antropológico.

Entra en picado

por aquella kénosis

que el Verbo aventuró

desnudamente,

de abismo en abismo,

hasta el foso fecundo de la muerte ${ }^{27}$.

Por otra parte, si la encarnación implica para Dios tocar la historia en la carne de Jesús, la muerte en cruz significa asumir las consecuencias de un determinado modo de vivir. Encarnación, entonces, no solo en la vida, sino también en la muerte, pero en una muerte que es consecuencia de un estilo de vida y unas opciones mantenidas hasta pagar el precio con la propia vida: Jesús murió como murió, porque vivió como vivió. Dado que, como dijimos en el punto anterior, la encarnación no es aséptica, desde ahí puede "entenderse" el tipo de muerte que sufrió Jesús: asesinado, en la plenitud de su vocación, por los poderosos. Y hoy sigue encarnándose en la muerte de tantos mártires del pueblo sufriente, como proclama dom Pedro en el poema "San Romero de América".

El ángel del Señor anunció en la víspera,

y el Verbo se hizo muerte, otra vez, en tu muerte;

como se hace muerte, cada día en la carne desnuda de tu Pueblo ${ }^{28}$.

Pero conviene aclarar que el Hijo de Dios sigue encarnándose en la muerte injusta de tantos y tantas para denunciar que no todo está permitido, no para sacralizar esa cruz. Es que el cristianismo en general, y el latinoamericano en particular, ha desarrollado, por momentos, una suerte de devoción a la cruz — ¿sin el crucificado? - , que pervierte peligrosamente ese signo central de la piedad. La única cruz que el Señor acepta y nos invita a cargar es la que viene

26. Para ampliar esta importante verdad teológica, subrayada por J. I. González Faus, ver M. Moore, Creer en Jesucristo. Una propuesta en diálogo con O. González de Cardedal y J. I. González Faus, pp. 303-316 (Salamanca, 2011).

27. Con Jesús, o. c., p. 53.

28. Antología, o. c., p. 65. 
de luchar contra la cruz ${ }^{29}$. Por eso, en un verdadero poema-manifiesto, denuncia y maldice toda cruz... que no es la cruz de Jesús: la que empuja a la resignación fatalista y alienante-"Maldita sea la cruz / que cargamos sin amor / como una fatal herencia"-, la que se vuelve opresión de los más indefensos - "Maldita sea la cruz / que echamos sobre los hombros / de los hermanos pequeños"-, la no combatida - "Maldita sea la cruz / que no quebramos a golpes / de libertad solidaria"-, la que se vuelve amuleto ofensivo - "Maldita sea la cruz / que exhiben los opresores / en las paredes del banco, / detrás del trono impasible, / en el blasón de las armas, / sobre el escote del lujo, / ante los ojos del miedo"-, la que prostituye el nombre de Dios - "Maldita sea la cruz / que el poder hinca en el Pueblo, / en nombre de Dios quizás. / Maldita sea la cruz / que la Iglesia justifica - quizás en nombre de Cristo-". Y cierra, exclamando, con ira profética: “iMaldita sea la cruz /que no pueda ser La Cruz!”30.

\section{3. “No sabes imponerte, Amor frustrado?”: encarnación y escándalo}

El tema de la cruz remite, en la teología y en la espiritualidad, al del sufrimiento del inocente y a la acción-inacción del Dios proclamado como Amor y Omnipotencia ${ }^{31}$. Claro que esta difícil cuestión, clave de la teodicea, no es abordada sistemáticamente en la poesía de Casaldáliga. Pero surgen algunas claves importantes. Ante todo, el poeta contextualiza la cuestión con dialéctico realismo.

¿Cómo

hablar de Dios

después de Auschwitz?,

os preguntáis vosotros,

ahí, al otro lado del mar, en la abundancia.

¿Cómo

hablar de Dios

29. "Ya hay suficiente mal en el mundo. Dios no quiere que lo aumentemos. Al contrario, quiere que lo combatamos. Vivir y luchar por la Causa de Jesús incluye combatir el mal y construir el bien, ahogar el mal con el bien (Rm 12,21). La cruz que el Señor Jesús nos invita a tomar si queremos seguirle no es una cruz que haya que buscar; es la cruz que viene de luchar contra la cruz: 'la cruz que la carne y el mundo echan sobre los hombros de los que buscan la paz y la justicia' (GS 38)". Espiritualidad, o. c., p. 218.

30. Con Jesús, o. c., p. 51.

31. "En la cruz aparece en directo el silencio, la inacción y, desde ahí, la impotencia o al menos la inoperatividad de Dios. La manifestación de esa inactividad e impotencia no tiene formalmente una dimensión liberadora ni tiene por qué generar esperanza en los crucificados, las víctimas. Pero si se la relaciona con la manifestación poderosa de Dios en la resurrección, entonces puede hacer creíble el poder liberador de Dios". J. Sobrino, La fe en Jesucristo. Ensayo desde las víctimas, p. 134 (Madrid, 1999). 
dentro de Auschwitz?,

se preguntan aquí los compañeros,

cargados de razón, de llanto y sangre,

metidos en la muerte

diaria

de millones... ${ }^{32}$

Con razón, explicita lo obvio, pero muchas veces ignorado: el lugar geográfico, social, económico, cultural, religioso..., desde donde surge la pregunta, condiciona y tiñe la respuesta. Así, desde el seno oscuro de esa realidad, el poeta se hace eco, retóricamente, de las preguntas que anidan en tantos creyentes vulnerados por los más diversos sufrimientos.

Y Tú, ¿no dices nada?, ¿no te enteras?

¿pides más cruz aún?, ¿más sangre esperas?,

¿no sabes imponerte, Amor frustrado? ${ }^{33}$

Más allá de la pregunta, "humanamente" legítima, que emerge desde las entrañas heridas, cierra el soneto: “¡Dios mío y nuestro y de Jesús, ¿por qué / una vez más nos has abandonado?!" ${ }^{4}$. Casaldáliga sabe que nuestro Dios, el Dios de Jesús, es un Dios que está del lado del sufriente, que no abandona a su pueblo oprimido. Y sabe que ha puesto en nuestras manos la historia. Por lo tanto, las causas de esos males habrá que buscarlas entre la libertad y la contingencia del hombre: "el sufrimiento... es simultáneamente un misterio y una connaturalidad en nuestra condición de seres finitos y mortales" ${ }^{35}$. Por eso, a esa pregunta retóricamente insolente, “¿no sabes imponerte, Amor frustrado?”, el mismo autor respondería: no. No sabe. El amor de Dios, el Dios que es amor, no sabe de imposiciones: seduce, alienta, insinúa y convoca a luchar contra esos males. Y es que la cruz de Jesús o es el fin de toda teología o es el comienzo de una teología nueva y radicalmente cristiana, más allá del ateísmo y del teísmo, que piensan a Dios en simple correspondencia y continuidad con el hombre. La cruz o es la muerte definitiva del Dios de Jesús, y de su proyecto del reino, o es la invitación a incorporar a nuestro discurso teológico el momento del fracaso de Dios en la historia... y desde el suyo, el nuestro ${ }^{36}$. Y a pasar de la imagen de un Dios intervencionista a un Dios discreto.

32. Antología, o. c., p. 110.

33. Ibid., p. 123.

34. Ibidem.

35. Espiritualidad, o. c., p. 199.

36. Cf. J. Moltmann, El Dios crucificado. La cruz de Cristo como base y crítica de toda teología cristiana, pp. 13-14, 353-358 (Salamanca, 1977). 
Ya para la iglesia primitiva supuso un arduo camino a nivel reflexivo y existencial el pasar de percibir la cruz como escándalo a pensarla como salvación. Pero J. Sobrino avisa que ninguna explicación debería intentar disolver esa dimensión de aspereza que tiene la cruz: "bien está buscar alivio para la razón escandalizada, pero mal está que ese alivio eliminase el escándalo" ${ }^{37}$, puesto que el hecho de que Dios dejase morir a su Hijo muy amado en vistas al bien mayor de la salvación, no es un dato evidente a priori, que pudiéramos deducir de nuestra preconcebida idea de Dios; muy por el contrario, solo $a$ posteriori y superando nuestra lógica meramente racional, podemos acercarnos a ese misterio ${ }^{38}$. La cruz es escándalo porque es muerte, porque es muerte de un inocente y porque ese inocente era el Hijo de Dios. Y porque da la vida por defender la verdad de Dios y la verdad del hombre... que le da muerte en nombre de ese Dios, o, mejor dicho, de $s u \operatorname{dios}^{39}$.

En definitiva, esa kénosis de la que venimos hablando es la que da razón de la aparente ausencia de Dios en la vida de Jesús, sobre todo, en el drama de la cruz, y permite interpretarla como revelación de la identidad solidaria de Dios con el hombre, sobre todo, del hombre sufriente ${ }^{40}$.

\section{Y la carne se hizo reino}

Si el misterio del Dios que se hace hombre es el fundamento del cristianismo, se entiende la importancia de la cuestión del reino, dado que esa causa es la que da sentido a la vida y a la muerte de Jesús de Nazaret. Entre la encarnación y la cruz, pues, el reino es la clave que ilumina su historia y que llena de contenido y de significado su resurrección. En fidelidad a la historia del Galileo, Casaldáliga nos presenta a un Jesús que, mientras revela el designio del Padre, critica toda forma de humanismo que pretenda instaurar un reino olvidando su último fundamento y condición de posibilidad, que es la paternidad de Dios; y en cuanto revela cuál es su voluntad histórica, critica toda Iglesia, toda teología y toda fe, que intente predicar un Dios sin reino.

\section{1. “Abel, Abel, ¿qué has hecho de tu hermano?”: reino y fraternidad}

En la prédica de Jesús, ese tema absolutamente central se presenta como una realidad en tensión: el reino llega con él y debe seguir llegando, ya-perotodavía-no. El reino es una realidad en devenir. Así también lo concibe nuestro poeta, apelando a la responsabilidad de todos los creyentes en la construcción de

37. J. Sobrino, Jesucristo liberador. Lectura histórico-teológica de Jesús de Nazaret, p. 298 (Madrid, 1993).

38. Cf. ibid., p. 185.

39. $C f$. M. Moore, Creer, o. c., pp. 459-460.

40. Cf. J. I. González Faus, La humanidad nueva, o. c., p. 214. 
este reino de fraternidad, definido por la inclusión y la denuncia de las distintas formas de exclusión. Uno de sus más bellos sonetos cierra con una pregunta que nos lanza el mismo Dios y que suspende el aliento del lector.

Quizá sea un Caín, pero es humano,

y por él, Dios, celoso, nos pregunta:

-Abel, Abel, ¿qué has hecho de tu hermano? ${ }^{41}$

Reinventa así esa historia, borrando, o al menos, cuestionando, los roles bien definidos entre buenos y malos, víctimas y victimarios. Porque, sea lo que fuere, "Caín" no deja de ser un hermano... y un humano, que

Lleva el destino a cuestas, con el saco, muerto el amor y la tristeza viva.

Le escuece el alma en el mirar opaco.

Es una soledad a la deriva ${ }^{42}$.

Con la misma intención de avisar contra una rápida auto-absolución en el compromiso de la búsqueda de una humanidad más humana, acerca al lector a la figura de Judas: "Judas, hermano Judas, compañero / de miedos, de codicia, de traición"43. La posibilidad de la entrega ( $c f$. Jn 13,21) es una amenaza latente en todo creyente.

Frustrado apóstol turbio del deseo,

lo que sabemos hoy, tú no sabías;

lo que esperabas tú del Galileo,

lo exigimos de Dios todos los días ${ }^{44}$.

Y sin decirlo expresamente, Casaldáliga señala todas esas posturas vitales que se sostienen en una expectativa mesiánica más mágica y mítica que jesuánica, que pretenden que sea Dios quien, "a golpe de milagros", resuelva los conflictos de la historia ${ }^{45}$. En cierta medida, el poeta excusa a Judas, porque "lo que sabemos hoy, tú no sabías". En efecto, Judas no alcanzó a saber que Dios no bajó a su Hijo de la cruz, que no intervino suprimiendo la libertad de quienes decidieron eliminarlo ( $c f$. Mt 27,40-43). Y si no evitó directamente el sufrimiento - el cáliz no pasó-, ni la muerte de su Hijo amado, en vano será que le exijamos que sea Él quien elimine los dolores de una historia que ya puso en nuestras

41. Sonetos, o. c., p. 11.

42. Ibidem.

43. Ibid., p. 49.

44. Ibidem.

45. A. Torres Queiruga ha dedicado gran parte de su producción teológica a corregir esas teologías y espiritualidades que se apoyan en la imagen de un Dios intervencionista. De un modo particular e in extenso, lo hace en Repensar la revelación. La revelación divina en la realización humana (Madrid, 2008). 
manos. Los clavos no se convierten en rosas y las piedras no se convierten en panes ( $c f$. Mt 4,3), a menos que el hombre ponga manos a la obra ( $c f$. Lc 9,13). Y también sabemos algo fundamental que Judas no supo: que la muerte no tuvo en Jesús la última palabra, ni la tendrá en nosotros..., pero eso no elimina el escándalo de la verdad penúltima: la real, aunque transitoria, victoria de la muerte y los verdugos ${ }^{46}$.

\section{2. “QQué Francisco aún os besa?”: reino y sufrimiento}

En la línea de Mateo 25,31-46, Casaldáliga identifica el dolor del pobre como el dolor de Dios en la historia. Más en concreto, es Jesús quien sufre en el leproso, que sigue siendo excluido del reino, no reconocido en su dignidad humana. "Leproso Tú y compañía, / carta de ciudadanía / nunca os acaban de dar"47. Se refiere a toda esa multitud de hombres y mujeres - ¿¿cuántos somos?, ¿cuántos son?" buen samaritano, gimen en los bordes del camino, en las cunetas de la historia, expulsados y excluidos, por la indiferencia y el egoísmo insolidario: "esa infinita legión / que sobrevive a la vera / de nuestra desatención" 49 . Al final del soneto, la cuestión se agudiza y se focaliza en pregunta dirigida a la Iglesia como primera responsable de hacer presente el reino: “QQué Francisco aún os besa? / ¿Qué Clara os sienta a la mesa? / ¿Qué Iglesia os hace de hogar?"50. Esta pregunta es una suerte de aviso, y de denuncia, para que la Iglesia no se vuelva autorreferencial. Su razón de ser es continuar el reino, iniciado por Jesús de Nazaret. Y tener sus sentimientos: dolerse con el dolor del otro, "porque tu soledad también es mía; / y todo yo soy una herida, donde / alguna sangre mana" ${ }^{51}$. Esos sentimientos empujan a una compasión activa: no solo sentir-con, sino también luchar-contra.

$\mathrm{Y}$ en otro poema, interpelante para todo pastor, para cualquier creyente, que es una confesión íntima, pero pública - "Yo, pecador y obispo, me confieso"52-, enuncia la dimensión eclesial de su fe, pero de una Iglesia que hunde sus raíces y recibe su impronta del Jesús histórico, de una Iglesia que se sabe reino-céntrica.

46. "Ante esta paradoja, la teología y la Iglesia toda debería hacer un alto, no escapar hacia el 'final feliz' de la historia (resurrección); cerrar los libros y contemplar - más que pensar - esa verdad desnuda, que es el Libro de la Vida abierto en la cruz de par en par (Lignum vitae): servirá, al menos, para no acostumbrarse y no dejar de escandalizarse ante tantos crucificados inocentes que sigue produciendo nuestra sociedad". M. Moore, Creer, o. c., p. 460.

47. Sonetos, o. c., p. 37.

48. Ibidem.

49. Ibidem.

50. Ibidem.

51. Antología, o. c., p. 78.

52. Ibid., p. 114. 
Yo, pecador y obispo, me confieso

de soñar con la Iglesia

vestida solamente de Evangelio y sandalias,

de creer en la Iglesia,

a pesar de la Iglesia, algunas veces;

de creer en el Reino, en todo caso - caminando en Iglesia- ${ }^{53}$.

Proféticamente crítico con la jerarquía eclesiástica, ¡de la cual él forma parte!, en otro audaz poema, dedicado a Juan Pablo II, titulado "Deja la curia, Pedro", lo invita, a él, a sus sucesores..., a la Iglesia toda, a descentrarse, desinstalarse y a marchar hacia los nuevos Getsemaníes.

Deja la curia, Pedro, desmantela el sinedrio y la muralla, ordena que se cambien todas las filacterias impecables

por palabras de vida, temblorosas.

Vamos al Huerto de las bananeras, revestidos de noche, a todo riesgo, que allí el Maestro suda la sangre de los Pobres ${ }^{54}$.

Nótese que "Maestro" y "Pobres", el nombre de Dios hecho hombre y el nombre del oprimido, ambos sin confusión, pero sin separación, están escritos con mayúsculas. Y casi como una súplica exhorta a Pedro, a los pastores, a mantener viva la utopía de Jesús de Nazaret y de su reino de colores precisos.

Diles, dinos a todos,

que siguen en vigencia indeclinable

la gruta de Belén,

las Bienaventuranzas

y el Juicio del amor dado en comida ${ }^{55}$.

Y pide a la Iglesia que no sea cómplice de los imperialismos que oprimen a los más pobres, en un escenario movible de los palacios de Pilatos y Caifás a nuestro continente empobrecido.

Legión de mercenarios acosan la frontera de la aurora naciente

y el César los bendice desde su prepotencia.

En la pulcra jofaina, Pilatos se abluciona, legalista y cobarde.

El Pueblo es solo un "resto",

un resto de Esperanza.

No Lo dejemos solo entre guardias y príncipes.

53. Ibidem.

54. Ibid., p. 90.

55. Ibid., pp. 90-91. 
Es hora de sudar con Su agonía,

es hora de beber el cáliz de los Pobres ${ }^{56}$.

Complicidad eclesial que, dolorosamente, recuerda en la vida, y la muerte, de Mons. Romero:

¡Pobre pastor glorioso,

abandonado

por tus propios hermanos de báculo y de Mesa...!

(Las curias no podían entenderte:

ninguna sinagoga bien montada puede entender a Cristo $)^{57}$

\section{3. "Fraterna y subversiva Eucaristía": reino y eucaristía}

Una de las metáforas más recurrentes en la obra de Casaldáliga, para hablar del reino, es la de la comensalidad ${ }^{58}$, la posibilidad de sentarnos todos a una misma mesa. En efecto, forma parte esencial en la construcción de ese reino, el desafío de "ser iguales en la alteridad"59, cuando "La verdad es que no tenemos vino" 60 . Entonces, hace falta "Uva pisada en nuestra dura historia, / vino final bebido a plena gloria / en la bodega de la Trinidad"61. Casaldáliga marca así la tensión escatológica hacia la venida del reino: el grano se va pisando y macerando en nuestro tiempo, pero el vino bueno solo se beberá al final, cuando Dios sea todo en todos ( $c f$. 1 Cor 15,28), cuando verdaderamente todos estemos sentados a la mesa, participando de la fiesta, sin excluidos, cuando sea definitivamente vencida la realidad que hoy se impone, porque "Rotas las alas, sueltos los chacales, / hemos cegado el curso de la vida / entre los varios pueblos comensales"62.

En esa tensión del ya-pero-todavía-no, el reino se va construyendo a ritmo de eucaristía, definida por nuestro autor como "fraterna" y "subversiva".

Llamados por la luz de Tu memoria, marchamos hacia el Reino haciendo Historia, fraterna y subversiva Eucaristía ${ }^{63}$.

56. Ibid., p. 90.

57. Ibid., pp. 65-66.

58. Una excelente introducción a este tema, desde la perspectiva bíblica, puede verse en R. Aguirre, La mesa compartida. Estudios del Nuevo Testamento desde las ciencias sociales (Santander, 1994).

59. Sonetos, o. c., p. 31.

60. Ibidem.

61. Ibidem.

62. Ibidem.

63. Ibid., p. 45. 
Lejos de toda lectura espiritualista - en el devaluado sentido de la palabra-, esas celebraciones que apuran la utopía son, para nuestro autor, el fruto de muchas manos, de muchas historias que convergen para formar un único pan; y son subversivas porque son memoria y actualización de la vida y la muerte de Aquel que no aceptó ni acepta el statu quo de injusticia en el que viven muchos hombres y mujeres.

Mis manos, esas manos y tus manos

hacemos este Gesto, compartida

la mesa y el destino, como hermanos.

Las vidas en Tu muerte y en Tu vida ${ }^{64}$.

Conmemoración de la muerte de Jesús, que sigue muriendo con el pueblo y para el pueblo, y que se vuelve memoria dolorosa y gloriosa en la eucaristía. Durante su celebración, Monseñor Romero fue "asesinado a sueldo, / a dólar, / a divisa. / Como Jesús, por orden del Imperio" ${ }^{65}$.

Tú ofrecías el pan,

el Cuerpo Vivo

-triturado cuerpo de tu Pueblo;

Su derramada Sangre victoriosa-

¡la sangre campesina de tu Pueblo en masacre

que ha de teñir en vinos de alegría la aurora conjurada! ${ }^{66}$

Y también como Jesús, el obispo salvadoreño tuvo que aprender a encarnarse en el pueblo sufriente, que será su maestro - "Los pobres te enseñaron a leer el evangelio" ${ }^{67}$-, para luego beber "el doble cáliz / del Altar y del Pueblo, / con una sola mano consagrada al servicio" 68 . Una sola mano, en la cual se unen "sin confusión, pero sin separación”, el Altar y el Pueblo - ambos con mayúsculas, otra vez-, la mística y la historia, el sacramento y la praxis..., ¡lo humano y lo divino! Porque, en definitiva,

La Eucaristía

que no es mesa

acaba siendo

pura blasfemia ${ }^{69}$.

64. Ibidem.

65. Antología, o. c., p. 65.

66. Ibidem.

67. Ibid., p. 66.

68. Ibidem.

69. Todavía, o. c., http://servicioskoinonia.org/Casaldaliga/poesia/todaviae.htm. 
Eucaristía que apunta más a la comunión que a la adoración, porque "comiéndote sabremos ser comida"70. Comulgar con su cuerpo implica comulgar también con su destino pro-existente ${ }^{71}$, por lo que la comunión invita al creyente a hacerse alimento para que los demás vivan humanamente.

El vino de sus venas nos provoca

el pan que ellos no tienen nos convoca

a ser Contigo el pan de cada día ${ }^{72}$.

\section{4. "Porque aprendí a esperar a contramano": reino y espera}

En la construcción de ese reino, inaugurado por la carne de Jesús, luchando por "Humanizar la humanidad practicando la proximidad" "3, y celebrando anticipadamente la victoria en cada eucaristía, el compás de espera lo marca la esperanza. Casaldáliga es un optimista no ingenuo, su esperanza es teologal y le permite sobrellevar lo evidente penúltimo, desde la convicción de que la(s) muerte(s) ha(n) sido escatológicamente vencida(s).

¿Dónde está tu victoria, muerte extraña?

¿Dónde está tu derrota, muerte amiga?

[...]

Juntos crecemos. Tú hacia el ocaso,

cumplida la misión que nos fecunda.

Nosotros hacia el día, por el "paso"

de tu garganta abierta... ${ }^{74}$

Sabe, por lo tanto, que la muerte vendrá; pero sabe también, porque lo cree, que pasará.

Vendrá. Saldrá de mí. La llevo dentro

desde que soy. Y voy hacia su encuentro

con todo el peso de mis años vivos.

Pero vendrá... para pasar de largo.

70. Sonetos, o. c., p. 45.

71. Cf. H. Schürmann, "La 'pro-existencia' como concepto cristológico fundamental", en El destino de Jesús: su vida y su muerte (Esbozos cristológicos recopilados y presentados por Klaus Scholtissek), pp. 267-301 (Salamanca, 2003).

72. Sonetos, o. c., p. 45.

73. "Humanizar la humanidad practicando la proximidad". Comunicación de Pedro Casaldáliga, en la recepción del Premio Internacional de Catalunya 2006. Disponible en http://servicioskoinonia.org/Casaldaliga/textos/textos/PremiIntCatDiscursCast.pdf. Consultado el 1 de mayo de 2016.

74. Antología, o. c., p. 124. 
Y en la centella de su beso amargo

vendremos Dios y yo definitivos ${ }^{75}$.

Claro que esa esperanza no nos ahorra el cargar en el mientras tanto la aridez de la pregunta, la angustiante sensación de Su ausencia, pero con la certeza - de fe - de que "La profunda soledad de tu abismo se ha llenado / con el grito del Dios crucificado" 76 . El poeta alude aquí a Jesús, que, en su muerte, hace experiencia de la -momentánea- superioridad del mal y del absurdo, y desde esa dolorosa ambigüedad cree, no luego de haberla entendido y superado. Así, nos invita a saber integrar en nuestro proceso creyente los fracasos, las frustraciones y las contradicciones, inevitables en el camino del seguimiento que es la fe. Desde el seno aparente, pero sufrido del abandono, se cree como Jesús y se cree en el Dios de Jesús ${ }^{77}$, desde una fe que convive con la pregunta.

¿Qué Dios es éste que muere,

Ausente que siempre busco,

Presente en aquel hondón

donde mi yo es todo suyo,

donde termina el vacío

de mi soledad y el mundo??

Y sabe también nuestro autor, por "carne ajena", sentida como propia, de la fatiga por la construcción del reino, cuando se debe pagar con la propia vocación la incomprensión de los que detentan el poder. Así lo expresa en el soneto dedicado a Leonardo Boff, recordándole que "Entre Roma y Asís, está el Calvario"79. Pero que también existe "todo un Continente, solidario / con nuestra fiebre y

75. El tiempo, o. c., p. 21.

76. Antología, o. c., p. 124.

77. "Desde esta convicción, creemos que la teología de la fe, cuando presenta la respuesta creyente, debería incorporar más seriamente el eco del grito de Jesús en la cruz en nuestra búsqueda, y también el posterior silencio del sepulcro: el sábado santo de quien ve morir sus certezas y todavía no ve el amanecer de la pascua. Saber permanecer en la crisis. Sin tremendismo, pero con el realismo de la fe: solo así se puede calibrar la hondura del drama de la soledad, verdadero espacio de irredención del hombre moderno, y la discreta oferta de compañía a la comunión trinitaria que abre el Hijo sufriente, como dadora de sentido; o el drama de tantos pobres que ven gastarse sus días en la tensión entre la utopía del Reino y el realismo de su dolor, que se llama hambre, marginación, exclusión, infra-humanidad". Cf. M. Moore, Creer, o. c., p. 463.

78. El tiempo, o. c., p. 45.

79. Sonetos, o. c., p. 61. Casaldáliga dedica al teólogo franciscano otros dos poemas "solidarios", en El tiempo y la espera: "Bendición de San Francisco a fray Leonardo Boff” (52-53) e "¿Y qué le diría, un año después, mi compadre San Francisco a fray Leonardo?” (54). 
nuestra teología" ${ }^{80}$. Con el apoyo de tantos y de tantas que luchan por la causa de Jesús, y desde la convicción con la cual comienza el soneto "Dice el Señor: 'Yo vengo y no tardo"" ${ }^{81}$, más allá de las contrariedades y de las persecuciones, Casaldáliga es un hombre de esperanza firme y realista. Por eso, concluye alentando a su hermano: "porque creemos que Su Reino avanza / más allá del pecado y de la muerte, / hablemos y vivamos de Esperanza" ${ }^{82}$. Y desde esa convicción, se siente él mismo obligado a "confesarse".

Yo, pecador y obispo, me confieso

de abrir cada mañana la ventana del Tiempo;

de hablar como un hermano a otro hermano;

de no perder el sueño, ni el canto, ni la risa,

de cultivar la flor de la Esperanza

entre las llagas del Resucitado ${ }^{83}$.

A confesarse y a esperar el reencuentro no solo con el Señor, sino también con los caídos en su nombre: "porque aprendí a esperar a contramano / de tanta decepción: te juro, hermano, / que espero tanto verLo como verte" ${ }^{84}$. Para cerrar este apartado, vale la pena citar por entero un poema que es un verdadero ideario y manifiesto sobre la esperanza.

Yo me atengo a lo dicho:

La justicia,

a pesar de la ley y la costumbre,

a pesar del dinero y la limosna.

La humildad, para ser yo, verdadero.

La libertad, para ser hombre.

Y la pobreza, para ser libre.

La fe, cristiana, para andar de noche, y, sobre todo, para andar de día.

Y, en todo caso, hermanos, yo me atengo a lo dicho: ¡la Esperanza! ${ }^{85}$

80. Sonetos, o. c., p. 61.

81. Ibidem.

82. Ibidem.

83. Antología, o. c., p. 114.

84. Ibid., p. 78.

85. Ibid., p. 54. 


\section{5. "Guerrillero del Mundo, de la Iglesia y de mí mismo": reino y pobreza}

En el contexto en el que Casaldáliga escribe, tan signado por el sufrimiento y la violencia, además de enarbolar la bandera de la esperanza, el poeta aparece como un gran pregonero de la paz. En efecto, para la construcción del reino, un arma nomás permite llevar nuestro autor: "Solamente el Evangelio, como una faca afilada" ${ }^{\circ 6}$. Con un grito, que recuerda el escalofriante grito de Romero en su última gran homilía, cierra su poema dedicado al obispo-mártir salvadoreño, recientemente beatificado: “inadie / hará callar / tu última homilía!”. Es decir, construcción del reino bajando las armas, suplicando iy ordenando! el cese de la violencia. Violencia que también es denunciada cuando Amerindia, en diálogo con la Guadalupana, desenmascara la codicia y la muerte, propiciada "en nombre de Dios".

Me abrieron en canal buscando plata

y han quebrado la quena de mi voz.

¿Será Dios de la vida el que me mata?

¿Ese Dios, Guadalupe, será Dios? ${ }^{87}$

Y si el evangelio es el arma de la paz, la desapropiación es el escudo que defiende del andar pesado. En un bellísimo poema con reminiscencias franciscanas y sanjuanistas, titulado "Pobreza evangélica", aconseja:

No tener nada.

No llevar nada.

No poder nada.

No pedir nada.

Y, de pasada,

no matar nada;

no callar nada ${ }^{88}$.

Pobreza y fragilidad que Casaldáliga descubre en carne propia, y se anima a abrazar. Como constructor de ese reino, el poeta conoce su debilidad, pero sabe también dónde residen su fuerza y su condición de posibilidad: "Mi opción de eunuco por el Reino ostento / sobre esta frágil condición de hombre, / capaz, con todo, de acoger Tu aliento" 89 . Y si bien es consciente y sufre el precio a pagar - "Por causa de Tu causa me destrozo / como un navío, viejo de aventura" 90 -, también es sabedor de que, en medio de sus oscilaciones y fragilidades, puede ostentar un crédito valioso. Así, desafiante, cierra magistralmente ese soneto.

86. Ibid., p. 35.

87. Sonetos, o. c., p. 25.

88. Antología, o. c., p. 35.

89. Sonetos, o. c., p. 39.

90. Ibid., p. 47. 
No pagaré mis deudas; no me cobres.

Si no he sabido hallarte siempre en todos, nunca dejé de amarte en los más pobres ${ }^{91}$.

Con estas armas y con estos sentimientos, Casaldáliga se descubre "al acecho del Reino diferente", que es don y gracia, que ya está y tiene que venir, que pide esfuerzo y reclama gratuidad, que es luz y es sombra, que convoca sentimientos de pertenencia y de extrañeza, que se relaciona, pero no se agota ni se identifica totalmente con la Iglesia, ni con la realidad presente (mundo), ni con las expectativas personales.

$\mathrm{Al}$ acecho del Reino diferente

voy amando las cosas y la gente, ciudadano de todo y extranjero.

Y me llama Tu paz como un abismo

mientras cruzo las sombras, guerrillero

del Mundo, de la Iglesia y de mí mismo ${ }^{92}$.

\section{Conclusión}

Si es escandalosamente verdadero que Dios tocó la historia en la historia y la carne de Jesús de Nazaret, por respeto a esa misma Palabra, la palabra del poeta debe ser igualmente veraz y sincera: "Si el Verbo se hace carne verdadera, / no creo en la palabra que adultera. / Yo hago profesión de claridad"93. Valiente, Casaldáliga asume el desafío - "Te llamarán poeta / para reírse de tus razones / que desentonan de su razón; /para zafarse de tu Evangelio / que les cuestiona a su propio Dios"-, y blande su palabra poética como profecía que anuncia y denuncia desde "dentro de Auschwitz". Desde dentro del sufrimiento del pueblo empobrecido, sí, pero empujado por una invencible esperanza. "Y, en todo caso, La esperanza siempre. / 'Poder decir palabras verdaderas / en medio de las cosas que perecen', / jen medio de la vida que perdura!"'94.

Así emerge su fe cristológica, empapada de lirismo, y su cristología evangélica que, partiendo del Jesús histórico, se abre al teocentrismo (Dios como misterio último) y se concreta en el reino-centrismo, entendiendo ese reino como la gran utopía de "humanizar la humanidad practicando la proximidad". Fe traducida en palabra poética, que nace del silencio y también allí concluye.

Servir bajo el día a día.

Creer contra la evidencia.

91. Ibidem.

92. Ibid., p. 17.

93. Ibid., p. 21

94. Antología, o. c., p. 49. 
Decir siempre una palabra

última de lucha, para

caer luego de rodillas

en silencio ${ }^{95}$.

Porque, en definitiva, reducido al unum necessarium, lo único que cuenta para nuestro poeta es el amor hecho historia en la historia, sobre todo, del pueblo crucificado. Entonces, la palabra, que ya se ha vuelto silencio, cede definitivamente al gesto.

Al final del camino me dirán:

- ¿Has vivido? ¿Has amado?

Y yo, sin decir nada,

Abriré el corazón lleno de nombres ${ }^{96}$.

\section{Referencias bibliográficas (poesías citadas)}

Antología personal (Madrid, 2006).

"Comadre de suburbio", pp. 21-22.

“Deja la curia, Pedro", pp. 90-91.

"Dentro de Auschwitz”, p. 110.

"Espérame también”, p. 78.

"Mujer de cada día”, pp. 17-18.

“¿Por qué me has abandonado?”, p. 123.

“San Romero de América, pastor y mártir", pp. 65-66.

"Yo, pecador y obispo, me confieso", p. 114.

Con Jesús, el de Nazaret (Madrid, 2005) (con J. L. Cortés).

"Maldita sea la cruz", p. 51.

"Y el Verbo se hizo clase", p. 21.

El tiempo y la espera (Santander, 1986).

"Atardecer", p. 45.

"El misterio", p. 75.

“Oh, Dios mayor", p. 74.

"Silencio hablado", p. 17.

"Ella vendrá", p. 21.

"Preguntas para subir y bajar al Monte Carmelo", pp. 35-36.

Sonetos neobíblicos, precisamente (Buenos Aires, 1996).

"En Éxodo", pp. 16-17.

"Y el Verbo se hizo carne", pp. 20-21.

"De Amerindia para Santa María", pp. 24-25.

95. El tiempo, o. c., p. 75.

96. Antología, o. c., p. 98. 
"Jesús de Nazaret", pp. 28-29.

"No tienen vino", pp. 30-31.

"Los diez leprosos", pp. 36-37.

"Eunuco por el Reino", pp. 38-39.

"Mi Cuerpo es Comida", pp. 44-45.

"Antes de que el gallo cante", pp. 46-47.

"Judas", pp. 48-49.

“Centinela, ¿qué hay de la noche?”, pp. 58-59.

"Esperar contra toda esperanza", pp. 60-61.

"Yo mismo lo veré", pp. 62-63.

Todavía estas palabras (Estela, 1989) (Disponible en http://servicioskoinonia. org/Casaldaliga/poesia/todaviae.htm).

"Dinos cuál es tu Dios, Jesús...".

"Deus Absconditus".

"La Eucaristía que no es mesa".

"Te llamarán poeta". 